\title{
NATIONAL YOUTH POLICY AND ROLE OF MEDIA
}

\author{
Muhammad Ahmed Qadri* \\ Naseem Umer**
}

\begin{abstract}
This article is an effort to reflect the role of media required to be played in the proper implementation of national youth policy in Pakistan. During a time of emergent numbers of problems and inadequate resources, Pakistan consider that the essence of promising future is to prepare youth to take on responsibilities and be socially, economically and politically empowered. But of course, for this huge mission a detail strategic plan and proper implementation is required that links framework and action plans for all youth and relevant stakeholders. While there are many other stakeholders connected with national youth policy, media is one stakeholder in this article, drawing our most attention. As the world is now moving towards globalization, we have witnessed the era of emerging trends. For example today the focus is more on knowledge based economies and social and economic networking, technology has been changed and is growing with the fast pace. This resulted in some different eco and social challenges. All around the globe, youth is actively involved in policy making because they know the growing challenges and changing environment better than the other age related segments. Considering the above point in mind, the author feels if the potential of youth is properly harnessed like in other countries, then this can bring a socio-economic revolution in Pakistan. On the contrary, if youth issues and ideas are not taken into consideration while policy making, this may result into one of the biggest challenge for the management in Pakistan in future. The young minds are needed to be shaped in a manner that they can live a better life with promising future and can benefit the whole society. With the ever changing circumstances, the growth and change in economy is constant. The rules and regulations regarding youth policies are needed to be implemented at national as well as provincial level, otherwise the nation has to face the serious outcomes in longer run. The increasing joblessness, among educated and uneducated youth will have negative impact on both economic and social life at individual and national level. The competition in economy is growing tough, far more educated youth now takes job for which they are overqualified. On the other hand, uneducated people can't seem to move up in the lifestyle ladder. This causes social disintegration, which results in poverty aggravation. This requires all related stakeholders to be responsible in implementation of youth policy across the nation.
\end{abstract}

Keywords: Media, national youth policy, stakeholders, education, global challenges, social impact

\footnotetext{
* Muhammad Ahmed Qadri, Ph.D. Professor \& Dean Faculty of Social Sciences, University of Karachi

${ }^{* *}$ Naseem Umer, Research Student, Department of Political Science, University of Karachi
} 


\section{Introduction}

Generally youth is considered as a stage of life after childhood and before maturity. More specifically, different dictionaries have defined youth as "a condition of being young" or "an era of age between childhood and adulthood". Although youth definition is quite understandable by all but law requires more specific explanations even for general terms. In Pakistan, the populace who falls under the age group of 15 years to 29 years, is considered as young population, hence declared as youth. It should be noted that for every country, the minimum age or the boundary age defining youth populace may differ.

For Punjab Youth Policy, term "youth" is considered as a period or an era of a person's life in which he/she tries to be more actively participate in the society and prepares themselves to become more responsible citizen and to impact the whole society in some way. Thus in more general terms it can be said that the phase of youth is the transformation of a child who is family dependent into an adult who is considerably more independent. After the independence the responsibilities enhanced, hence the government was expected to make certain policies and services specifically targeted to this age group that can direct youth towards society building. ${ }^{1}$

It should be noted that there is no precise and specific definition of youth in law. The period of youth for a person can be seen as transition phase, where he or she transitions into mature and self-sufficient person. However in such transition, young people are more vulnerable and exposed to different option that comes with different level of risks. The responsibility of making their own decisions that can affect their lives dramatically, is a huge burden for naïve young people. ${ }^{2}$

Youth policy for Punjab also discusses the limitations or factors that are possibly ignored in defining the age bracket. For example; variables like gathering information or maturity of one person may differ from another and thus two young people of same age can make different set of choices. Same goes for the two persons belonging to different background, culture, cities, lifestyles, education etc. however these above mentioned variables are more qualitative when implied. For this reason, Development practitioners consider a particular age unit that can be easily measured or identified so that the implication of youth policy can be easily done. ${ }^{3}$

Other variables defining age brackets for youth can be;

- the age limit of child benefits- when one passes the age defined by law for child benefits policies, then technically he/she shall be considered as youth and should entitled to youth benefits.

\footnotetext{
${ }^{1}$ Cambridge Advanced Learner's Dictionary \& Thesaurus (Cambridge University Press). (n.d.). Youth. Retrieved from Cambridge Dictionary: http://dictionary.cambridge.org/dictionary/english/youth

${ }^{2}$ UNESCO.org, 2016

${ }^{3}$ (C) 2016 Oxford University Press. (n.d.). Youth. Retrieved from Oxford Dictionary:

https://en.oxforddictionaries.com/definition/youth
} 
- The end of full-time compulsory schooling- for different countries, there are different grades of compulsory schooling.

- The voting age and the minimum age for standing as candidates in elections.

While these various indicators define adulthood in much broader terms, social analysts consider "age" as one and only working indicator of youth because of its tangibility. The United Nation defines youth as people who fall between the age brackets of 15-24 years, but according to Pakistan Government official standards, different cultural and social factors affect defining these age brackets and thus facilitating these factors, youth in Pakistan are defined as the populace between the age brackets of 15-29 years.

Apart from above mentioned variables, in simpler terms it has been said that youth is the time when young people become independent and financially stable. But if we accept this definition of youth then there is no doubt that we are ignoring certain other factors like education, graduation, job experiences and career involvements which can make a person of the same age, more financially stable than the other.

Increase in the length of studies (especially in our society, students tend to have increased participation in higher education and may have more than one degree), combined with difficulties in getting a first job and access to affordable housing have increased the length of the transition from youth to independence, especially in our society, thus explains the official age of youth in our country is 15-29 years. ${ }^{4}$

\section{Demographics}

As of $1^{\text {st }}$ January 2017, the population of Pakistan was estimated to be $194,931,848$ people. This is considered as an increase of approx. $2.10 \%$ compared to the population vaguely recorded in a year before 2016 that is 190,916,866. As of the beginning of 2017 according to web research it has been projected that Pakistan has the following population age distribution:

In absolute figures (estimate):

- $69,060,455$ young people under 15 years old $(35,475,647$ males/33,586,757 females) that makes about $35.428 \%$ of the total population.

- 117,653,066 persons between 15 and 64 years old (60, 766, 105 males / 56, 886,961 females) that makes about $60.356 \%$ of the total population.

- 8218327 persons above 64 years old (3,890,840 males/4,325,538 females) that makes about $4.216 \%$ of the total population.

\footnotetext{
${ }^{4}$ Creative Commons Attribution-NonCommercial-NoDerivs . (2014, April 10). Pakistan. Retrieved from Youth Policy: http://www.youthpolicy.org/factsheets/country/pakistan/
} 
According to the Population Labor Force Survey conducted in 2006, the population of youth in the country was recorded about 41.81 million that is $27 \%$ of the total population of the country, which shows a massive increase in a 10 year period..$^{5}$

In our country, youth makes the greater share of working population. This may lead to certain positive and negative impacts. On one hand we have more energetic, more updated, more flexible workforce that can help the economy to flourish. On the other hand the competition has become so tough that good employment opportunities have become limited. Fewer opportunities results in depression among youth. If proper economic opportunities are not provided to youth, then the energy of youth can be a greater threat to the society. It has been evident that the most of the recent suicide attacks done in Pakistan are conducted by young naïve minds of age 15-24 who can be easily manipulated. So this age needs such policies that can direct them towards the good of society which the authors believe is the biggest challenge in policy development and implementation.

Statistics on youth population extracted from the survey are given below. Salient characteristics of the youth population are:

Proportion of males and females is about $50 \%$ each. Approximately $67 \%$ of the young population lives in the rural areas and $63 \%$ of the young population (26.27 million) is educated or considered literate. Out of the 37\%- the segment of illiterate population (15.57 million), about $65 \%$ (10.13 million) are females and $35 \%$ are male. Approximately $49 \%$ (20.32 million) of the population constitutes labor force while $51 \%$ (21.51 million) is "out of labor force". The "out of labor force" population comprises of 6.89 million students and 14.03 million (including 13.82 million females as households.) Labor force can be devised in:

- $\quad$ Agriculture (about $37 \%$ of L.F),

- $\quad$ Retail trade and restaurants etc. (about $15 \%$ of L.F).

- Community, social and personal services (about $11 \%$ of L.F.) and

- $\quad$ Storage and communications (about 6\%).

\section{Role of Media}

Given the significance of youth in the progression of any society, Pakistan Government has officially initiate national youth programs and policies which aim to provide better means and healthy environment to youth for their optimal economic growth and social development. The policies are especially designed in a manner that will motivate the young populace to participate in the main stream of the practical life with creative opportunities. This will yield benefits for both- the society will benefit from youth's

\footnotetext{
${ }^{5}$ Pakistan Population. (2017, 01 02). Retrieved from Country Meters: http://www.countrymeters.info/en/Pakistan/
} 
efforts and participation, while youth will cater better opportunities to have a successful life. ${ }^{6}$

The role of media in this regard is undoubtedly, momentous. The government has an official ministry of youth which tend to release policies and opportunities for youth in different fields from time to time. Though it has been observed that there is a serious lack of communication that creates a distressing gap, media can be used in its conventional ways to fill this communication gap. While media can help in creating awareness and share the newly release opportunities to young populace, it can also benefit the government by helping in proper implementation and keeping a check on the right usage of policies. ${ }^{7}$

Media can be helpful in shaping the naïve minds of youth and can play a role in character building. TV/ radio/ media programs/ media campaigns of all sorts can include youth and elders, leading to good moral lessons. Talk shows can involve young people so that their issues and challenges can be properly addressed. Ministry of youth affairs also tries to attain objective through public and private media by asking them to pledge initiatives envisioned under youth policy or by asking them at least to start youth channels or youth programs. Media can allocate prime time for youth programs that can help in character and moral building while PTV may start a specific youth channel addressing only youth challenges and issues. ${ }^{8}$

It has also been declared in National Youth Policy that as youth discovers the world of practical life with enthusiasm and curiosity, they are more open to relative impressions and vulnerabilities. As their mind is still naïve, it is considered as a responsibility of society to shape their minds that could benefit their individual beings and society as whole. National Youth policy finds this vision necessary to mature and steer the development of youth in line with Islamic values, the ideology of Pakistan and the norms and aspiration of Pakistani society and culture. To achieve this desired objective, one can easily identify the importance of role of media and specifically of social media in shaping mindset in this regard. Without any doubt, there are number of challenges that need to be addressed for proper implementation, media while playing responsibly, can assist in long run. ${ }^{9}$

In order to understand the diversion of youth policy, we must look out to the strategies and goals set at sub divisions of national youth policy; that is provincial youth policy. Here, it shall be declared that this piece of article restricts the writers to contemplate certain limited points of each provincial policies that are considered to be interconnected or interlinked with the media and henceforward are discussed.

\footnotetext{
${ }^{6}$ Rakhra, K. (2008). An Inquiry into the Suicide Terrorism: Psychological Perspectives. New Delhi, India: Institute of Peace and Conflict Studies.

${ }^{7}$ Cutler, D. M., Glaeser, E. L., \& Norberg, K. (2001). Explaining the rise in youth suicide. Harvard Institute of Economic Research, Paper No. 1917

${ }^{8}$ Punjab Youth Policy. Lahore: Government of Pakistan (2012).

${ }^{9}$ Creative Commons Attribution-NonCommercial-NoDerivs . (2014, April 10). Pakistan. Retrieved from

Youth Policy: http://www.youthpolicy.org/factsheets/country/pakistan/
} 
Strategies for youth policies of each province centered on the three main goals:

a) Economic Empowerment

b) Social Empowerment

c) Political Empowerment

\section{Economic Empowerment of Youth}

The economic empowerment for youth provides following guidelines to follow;

1. Diversification of employment sectors creating livelihood opportunities among youth

2. Comprehensive awareness to youth about the employment sector and available jobs

3. Mapping of skills and demands of multiple sectors in the job market

4. Creating a program for certified and standardized technical training that can help both literate and illiterate youth like skill development and vocational training

5. Providing options for hassle free loans for startup businesses

6. Encouraging youth to participate in local exhibition and trade fairs and use as a platform to present their talents

7. Encouragement of entrepreneurship for youth by developing training programs for entrepreneurship Skills and by providing opportunities

8. Gender equity \& equality and promotion of rights of the vulnerable youth groups.

9. Internships, on-campus job and job placement.

The above guidelines are somehow followed by all provinces in one way or other but they have been summed up to portray a general approach of Government. ${ }^{10}$

\section{Role of media in Economic Empowerment}

As mentioned above, the main objective that can be attained by the use of media will be the communication. In this regard, the second guideline under the heading of economic authorization, "the comprehensive awareness to youth about the employment sector and available jobs" can be conquered effortlessly. The 'Rozgar' scheme released by government can be a good example here.

Sindh Youth Policy considers to create awareness through the short-term strategies of generating demand among youth and other stakeholders on the need for information through formation of peer groups, job surveys and employment trends, organizing seminars and conferences and finally by running media campaigns. During this phase,

${ }^{10}$ Sindh Youth Policy. Karachi: Government of Sindh, (2016) 
the Sindh department will mobilize technical and financial resources of stakeholders like the ILO, SPDC, STEVTA, Labour Department, and corporate sector, NGOs related to skill development, British Council and Bargad, electronic and print media, the University of Karachi and the University of Sindh.

The mid-term strategies include creating a centralized Information that is a system for Youth Development \& Job Data which is entirely based on employment opportunities for youth with the partnership of the public and private sector to guide and counsel jobseeking youth, and establishment of a job bank. The Information-System for Youth Development will be a comprehensive resource on who's who and what's what on Pakistan in the field of youth development, while the Job Data base is documentation of information relating to job opportunities for youth. The progress review will be undertaken on quarterly basis and evaluation will be done after 1.5 years and 3 years. ${ }^{11}$

Creating a program for certified and standardized technical training that can help both literate and illiterate youth like skill development and vocational training can be improved by the means of media. The government intends to assign high priority to promote technical education in all the provinces. For this intend, crash program would be launched to impart technical education to unemployed educated youth and then provide micro-credit to them so that they can become self-employed. The concepts of 'job bank' and 'online employer' are suitable in this repute. These concepts will promote youth empowerment by utilizing the full resources of today's given social media power.

The Government will arrange hassle free loans provided for technical and vocational training recipients, when needed on merit basis, with the help of private sector to implement such programs throughout the country. Female youth will be especially provided greater access to loaning facilities. To break taboos attached with technical and vocational education, the Government will arrange public service messaging, campaigns and Information Education Communication (IEC) materials to underscore the need for decent work among the youth. An example of such media campaign is 'Khushaal Kisan' in Punjab, which provides information about the educational programs provided to farmers as well as tend to give small loans to farmers.

Moreover, the Government considers it equally important that both literate and illiterate trainees of technical and vocational programs are properly certified; to duly win over access to national and international markets. ${ }^{12}$

\section{Social Empowerment of Youth}

The social empowerment for youth provides following guidelines to follow;

1. Providing education and general awareness about youth rights and youth development.

\footnotetext{
${ }^{11}$ Balochistan Youth Policy. Quetta: Government of Balochistan, (2015).

${ }^{12}$ Punjab Youth Policy. Lahore: Government of Pakistan, (2012).
} 
2. For better future, health is an important factor for youth, so medical guidance shall be provided.

3. Promoting trend of Youth Volunteerism and Community Service among young populace.

4. Promotion of Sustainable Peace and Development in society.

5. Assisting young people in the family planning and providing them financial ways to sustain and support their families

6. Aiding in peaceful living with cultural and regional diversity.

7. Enhancing the role of local languages, arts, music, sports like PSL to promote sense of unity and nationality.

8. Supporting and directing youth towards success by improving their morale, helping them finding their strengths, overcoming their weaknesses, identifying the opportunities that can lead to a better life.

9. Special programs for youth in prison shall be introduced that can help the young prisoners to rehabilitate and know the given opportunities $\mathrm{t}$ a better life. Also with training and education, certain incentives shall be included that can motivate them to learn.

10. Certain special programs for handicapped or disabled youth shall be included so that society could benefit from their talents and skills.

11. Pakistani woman is so skilled and talented that it will be unfortunate for the society of their gained talents and skills go wasted. Education of society is needed to pursue the gender equity at work and in general. Also rules and regulations that provide safe environment for career oriented females at work is required to introduced and implemented throughout.

\section{Role of Media in Social Empowerment}

Among all the other essential extents of social empowerment, education and health are two prime levels that can't be neglected at any cost. For education, where the main goal is to provide uniformity among the basic education system throughout the country, the role of media seems a little less significant than the execution of uniform education. It can be said that in this concern, the implemented policies and achieved targets are more likely to reap the fruit than the communication and media related programs.

However, for health sector, the goal is slightly different and aims at providing a collaborative effort of related departments, civil society and corporate sectors so that the maximum physical, mental and sexual wellbeing of youth could be attained. The policies included under health section involve protection from hazards, survival if exposed and other social health related needs like development of child, sexual wellbeing, threats of early marriages, family planning etc. ${ }^{13}$

\footnotetext{
${ }^{13}$ FATA Youth Policy. FATA Secretariat, (2014).
} 
For this purpose, 'Youth Helpline' has been made in Sindh to counsel adolescents on their health and reproductive issues. Additionally social campaigns on medical health awareness and about the well-being issues like hygiene are also undertaken. Government, with the support of media creates awareness programs on the issues of drug use, tobacco use, aids, hepatitis, sexually transmitted diseases, etc. Nowadays, an ad related to injurious effects of smoking is being aired on national channels to prohibit the use of tobacco. Also government runs youth-led mass awareness campaigns for promoting family planning in the country with the help of print and electronic media.

Here, at this point, it shall be noted that the culture of society plays an important role in maximizing the benefits of government policies. On one hand where it is appreciable that Sindh Government has made a 'youth helpline' to cover mental and sexual issues of youth, the other side of society condemns such policies. On one hand there is no doubt that family planning ads promote youth wellbeing but on other hand PEMRA had to ban the marketing of contraceptives. It is still a taboo in Pakistan to talk about sexual health of young adolescents' boys and girls while other developed societies consider it as one of their basic rights. ${ }^{14}$

Media can also play the role in connecting youth with sports, tourism and heritage. The youth policy encourages the increase usage of social media to communicate the youth about historical places and interest local places that can benefit the tourism overall. For promotion of local arts and music, many business and management schools introduced entrepreneurial assignments associated to arts and music concerts. For sports, we have special teams of age under 18, that not only get the exposure but also their skills and talents are polished that help them to attain expertise in their relate fields. Also to promote the essence of sportsmanship, many private corporations tend to run sport events or sponsor them locally. In addition to that, massive amount of funds are generated with the help of private businesses to run youth-led mass campaigns by endorsing sports heroes and celebrities.

\section{Political Empowerment of Youth}

Political empowerment of youth can be achieved by devising models that train students at early age to become politically aware in future. Pakistan believes youth is the future of the country.

Pakistan is proud of its youth, particularly the students who have always been in the forefront in the hour of trial and need. You are the nation-builders of tomorrow and you must fully equip yourself with discipline, education, and training for the arduous task lying ahead of you. You should realize the magnitude of your responsibility and be ready to bear it. ${ }^{15}$

\footnotetext{
${ }^{14}$ Ministry of Youth Affairs. National Youth Policy. (Islamabad: Government of Pakistan, 2008)

${ }^{15}$ Quaid-e-Azam Muhammad Ali Jinnah 31 ${ }^{\text {st }}$ October 1947
} 
Keeping that in mind, Government of Pakistan wants to invest in the political development of youth as well. Besides the fact, that today's youth is going to be the leaders of tomorrow, good administration around the world also make nation politically aware as whole. So that they could have their own opinions or make decisions for their own betterment by stating facts. So in order to shape the future leadership of Pakistan models have been devised for elected student councils to promote pro-peace, gender equity and leadership centered actions on campuses. In Sindh there is a reservation of $5 \%$ quota in the elected local bodies for eligible youth. ${ }^{16}$

To have political mindfulness, students can be taken to exposure trips to Parliaments or provincial assemblies. This will increase their knowledge and thus can chose politics in later life. Youth led campaigns can make a drastic positive impact on youth for voter registration and voting process.

\section{Role of Media in Political Empowerment}

Although the role of media is not clearly stated in empowering youth politically, except for the youth led campaigns to promote voting, but media still can be very beneficial in the long run. The objective of political empowerment is to teach sense of active citizenship and self-value, respect for rule of law and participation in the community and Government decision making at municipal, provincial and national levels. There is absolutely no doubt, that democratic and politically empowered youth is need of the hour. In Pakistan, students who like to join political campaigns at university level are forbidden by teachers or parents. This reflects a clear issue that nation don't trust the genuineness of politics. Media can help by changing this mind set. Of course it would require a longer time period to reshape the intellect, but considering the issue of distrusting politics, the author feels a distinctive media campaign is immediately required to rebuild the trust on politics.

\section{Challenges that need consideration}

While the national and provincial youth policy involves a detailed strategic plan, highlighting the targets and annual tasks, there are certain derivatives that cannot be neglected as they are going to effect the policy implementation in one way or the other. The foremost challenge considering today's situation will be going young populace to live in peace and harmony and overcome the sectorial hate. The promotion of fundamental principles of the creation of country is required once again; unity, faith and discipline.

A bigger economical challenge is to engage the youth in economic activities, as youth comprises of the major portion of population. If it is not properly catered, then this demographic dividend may result in economic dividend that will negatively impact the society. In this regard, the basic question is "how" the employment opportunities for youth will be created?

${ }^{16}$ Sindh Youth Policy, (2016) 
Another issue is considering the rural populace of our country and their issues. Most of the rural youth has failed to attain the basic education. One of the issues is to create such environment that can facilitate this segment of youth, this might involve generating youth literacy programs and ensuring their reach to target market so that youth's full potential can be utilized.

FATA youth along with the above mentioned challenges, face some more challenges based on their different geography, culture and politics. They have to deal with the spread of terrorism / radicalism, lack of educational facilities, unemployment and the lack of political empowerment at the local level. ${ }^{17}$ Due to the lower affiliation, the citizens feel most deprived and discriminated against as compared to other provinces. Government needs to build a positive relation with them based on trust and belief. The purpose of the FATA Youth Policy is to counter this attitude with a more optimistic and tolerant view towards life and society. The FATA Youth Policy hopes to give an effective direction to its youth in living a purposeful life and participating as responsible members of the community. Thus, this policy aims to help channelize the energy of the FATA youth into a progressive force, who shall work towards the improvement of their communities and society as a whole. It endeavors to do this by providing an enabling environment for social, political and economic empowerment. It also aims to focus and invest in nation building, patriotism, social cohesion and volunteerism amongst the FATA youth, in order to develop a new cadre of youth, encompassing these value systems. Though the question is still the same, how and when it could be achieved?

As compared to Sindh and Punjab, total number of employed and unemployed people has increased in Balochistan over the past few years indicating an increase in the workforce. Total civilian labor force in 2012-13 was 2.58 million which has increased to 2.85 million in 2013-14. Moreover, youth living in low deprived areas such as Quetta, Pishin, Jaffarabad and Sibbi rank unemployment highest. This shows that there is a need to develop infrastructure and increase employment opportunities in these areas. It is imperative that the economic empowerment of youth is synergized with social uplift of young individuals who are progressive, egalitarian and sensitive to common good of the society. Social challenges being faced by the youth of Baluchistan include education for youth development, integrated health and sports, drug addiction, gender biasness and barriers for male and female youth, peace building and cohesion, sense of corruption/nepotism/social injustice, youth physical and psychological insecurities, promotion of culture and local art, discrimination against minorities/ marginalized youth, suicide among youth and lack of youth activism and volunteerism.

While the above discussion on youth policy has included provincial youth policies for Sindh, Baluchistan, Punjab and FATA, but Khyber Pakhtunkhwa has been deprived in this regard. KP government has announced first ever youth policy on November 282016 by establishing youth commission for empowerment of the youth to plan and devise strategy for their bright future and carrier progression. While other provincial government revealed a complete strategy, Khyber Pakhtunkhwa government hasn't

${ }^{17}$ Pakistan Tehreek-e-Insaf. (2016, November 28). KP government has announced first ever youth policy in $K P K$. Retrieved from Insaf: http://www.insaf.pk/news/khyber-pakhtunkhwa/item/1793014-kp-governmenthas-announced-first-ever-youth-policy-in-kpk 
made it yet official. In order to implement the national youth policy, Government of Pakistan should take every province in consideration and should suggest equal execution throughout.

\section{The Challenge for Media}

Media has also identified that the budget allocated for youth development and youth policy is unclear which has been very irresponsible behaviour of the government. Although now the responsibility is held by the provincial government but still the budget is unclear, which has given the entry to corruption in the departments. 